\title{
A (IM) POSSIBILIDADE DE CONTROLE SOCIAL NO CAPITALISMO
}

\author{
José Eduardo de Santana Macêdo ${ }^{1}$ \\ Marília Mendonça Morais Sant'Anna
}

\section{RESUMO}

A corrupção política, as discussões sobre a necessidade de ética na política e os questionamentos quanto à efetividade dos órgãos de controle no combate e prevenção da corrupção ensejaram a pesquisa sobre o controle social. O capitalismo nunca foi uma organização política democrática. Atualmente, sua crise econômica despreza a vontade popular para atender interesse dos grandes especuladores, fazendo regredir o ambiente democrático estabelecido. A efetivação do controle no país é muito difícil, em virtude da supervalorização da forma mercadoria, com a chancela do Estado. O resultado esperado é proporcionar uma oportunidade de reflexão sobre este assunto, considerado de extrema relevância.

Palavras-chave: Capitalismo, Controle Social, Corrupção, Estado, Ética.

\section{THE (IM) POSSIBILITY OF SOCIAL CONTROL IN CAPITALISM}

\begin{abstract}
The frequent political corruption scandals, the discussions about the need for ethics in politics and the questions about the effectiveness of control agencies in fighting and preventing this type of corruption, motivated this research to be developed on social control. It turns out that the effectiveness of this control in a country under the capitalist mode of production is very difficult, because of the overvaluation of the commodity form with the seal of the State. Capitalism has not always and inevitably been a democratic political organization. Currently, the economic crisis of capitalism passes over the popular will in favor of political interests of large speculators, regressing already established democratic environment. The major challenge is the reflection on the subject in order to determine whether, within capitalism, you can get a space where civil society can exert control over the government's actions or, necessarily, it is essential to overcome capitalism. Thus, it is expected to provide an opportunity for reflection on this subject, considered as of extreme importance.
\end{abstract}

Keywords: capitalism, social control and State

\section{INTRODUÇÃO}

O presente estudo trata da (im)possibilidade do controle social no capitalismo, em função da posição do Estado nesse modo de produção.

\footnotetext{
${ }^{1}$ Mestre em Direito Constitucional pela UFC, Doutorando em Direito Político e Econômico, e-mail: eduardomacedo.msc@hotmail.com

${ }^{2}$ Mestre em Direito pela PUC/SP, Doutoranda em direito político e econômico pela Mackenzie, e-mail: mmmsantanna@hotmail.com
} 
O controle social das atuações e nas atuações do poder público, que fora instituído a partir da promulgação da Carta Magna de 1988, conferindo aos cidadãos o poder de interagir com a gestão pública por meio da fiscalização, do monitoramento e avaliação das ações governamentais, permitindo, assim, o efetivo exercício da cidadania, que é o fundamento do Estado Democrático de Direito. Diversos foram os mecanismos postos à disposição dos cidadãos para que fosse possível o exercício do controle social, como o conselho de gestores de políticas públicas, as ouvidorias, o observatório social, o orçamento participativo e a audiência pública. Entretanto, para que esses mecanismos sejam eficientes, é imprescindível uma transparente e também é necessário que haja uma qualidade nessa participação.

O ponto nodal da investigação do controle social é o capitalismo. Nesse modo de produção, a estrutura econômica é a base real sobre a qual se erguem as relações sociais e jurídicas.

A prima facie, em virtude de o Estado ser o garantidor da mais valia da mercadoria, e, consequentemente, das explorações realizadas em função da busca inexorável do capital, ele se fragiliza e tende a se render aos caprichos da minoria exploradora. Assim, nesse contexto, o administrado se depara com óbices para exercer o controle social do Estado.

$\mathrm{O}$ interesse pelo tema do presente artigo surgiu em decorrência dos conhecimentos adquiridos acerca do capitalismo e dos grandes filósofos do Direito, especialmente ao realizar um estudo pormenorizado do livro Estado e forma política, de Mascaro. A intenção foi ressaltar os impactos desse livro no objeto de pesquisa, Controle Social das políticas públicas: uma leitura a partir da transparência administrativa.

Inicialmente, é apresentado um resumo sistemático do livro Estado e forma política, do Prof. Alysson Leandro Mascaro, no qual foi detalhado cada capítulo, com interlocuções dos autores e, também, interligações com outras obras do supracitado autor.

Na sequencia deste artigo é abordado o tema a (im) possibilidade do controle social no capitalismo, com a exposição de motivos, a destacada importância da transparência administrativa, as dificuldades da efetividade do controle social no modo de produção capitalista e, ao final, embora se vislumbre, nos dias atuais, certo progresso dos indivíduos no exercício do controle social das ações do poder público, ainda há uma grande dificuldade de exercê-lo de forma plena. Ao final, a exposição crítica é no sentido da superação do capitalismo, com o intuito de atingir a igualdade material, a democracia e a cidadania plena.

Para alcançar o objetivo proposto, foi empregada, como procedimento metodológico, 
a pesquisa exploratória descritiva, com o objetivo de identificar e obter informações sobre as características do assunto, através da leitura de artigos, livros, teses, dissertações e sites relacionados ao tema. Consiste em uma pesquisa qualitativa quanto à abordagem do problema, visto que a intenção é a de contribuir demonstrando a importância do controle social das atuações administrativas.

\section{A (IM) POSSIBILIDADE DO CONTROLE SOCIAL NO CAPITALISMO}

Os cidadãos sofrem com a manipulação das informações, sem que haja, da sua parte, a percepção disso, pois há um jogo político por trás, dando a falsa impressão de autonomia ou, ainda, mediante informações prestadas após sofrer recortes com reduções que, não somente mudam o sentido em relação ao todo, como podem distorcê-lo completamente. Trata-se de uma inversão no valor da informação ao indivíduo, fazendo-o pensar limitado sob determinada ótica, como, aliás, frequentemente ocorre nos casos de distorção.

A efetiva participação do povo na tomada de decisões administrativas permite um maior grau de correspondência entre o interesse público primário do Estado e as ações administrativas. Para tanto, é indispensável a maximização da publicidade, incrementando os níveis de conhecimento e fiscalização da atuação da administração pública.

O Brasil não possui tradição no controle social das ações do poder público. Dentre os possíveis fatores que podem explicar tal "apatia" social (participativa) estão o processo de formação histórica, as elites (política e econômica), o modo de produção capitalista (os detentores do capital, validados pelo Estado, iludem os indivíduos como sujeitos de direito, mas não passam de mercadoria de troca) e a ideia de que não se deve discutir a (e nem mesmo participar da) política do país (pois há certo conformismo em relação à mudança de rumos para melhores).

Embora o Brasil disponha de uma Norma Constitucional ainda jovem com apenas, com apenas 30 anos de vigência, os legisladores constituintes reunidos definiram no Preâmbulo da Carta Magna a destinação e os princípios para regerem o futuro e as relações do Poder Público com a sociedade quando instituíram o Estado Democrático:

Nós, representantes do povo brasileiro, reunidos em Assembleia Nacional Constituinte para instituir um Estado Democrático, destinado a assegurar o exercício dos direitos sociais e individuais, a liberdade, a segurança, o bemestar, o desenvolvimento, a igualdade e a justiça como valores supremos de uma sociedade fraterna, pluralista e sem preconceitos, fundada na harmonia 
social e comprometida, na ordem interna e internacional, com a solução pacífica das controvérsias, promulgamos, sob a proteção de Deus, a seguinte CONSTITUIÇÃO DA REPÚBLICA FEDERATIVA DO BRASIL (BRASIL, 1988).

Na mesma senda, cuidaram, pois, os Constituintes de consolidar como cláusula pétrea, de forma clara de quem os entes federados são servos:

Art. $1^{\circ}[\ldots]$

Parágrafo único. Todo o poder emana do povo, que o exerce por meio de representantes eleitos ou diretamente, nos termos desta Constituição. (BRASIL, 1988).

Mesmo com a força normativa do texto constitucional, sempre reivindicado e difundido, delineia-se que de forma ainda incipiente, há um aumento do envolvimento dos membros da sociedade nas arenas de debates públicos; por isso a importância da divulgação dos instrumentos de participação à sociedade.

Teoricamente, o aprofundamento da democracia no Brasil tem exigido dos órgãos e entidades públicas a adoção de modelos de gestão que ampliem a sua capacidade de atender, com mais eficácia e efetividade, as novas e crescentes demandas da sociedade brasileira. Não obstante os significativos avanços alcançados nos anos recentes, a administração pública ainda necessita aperfeiçoar seus sistemas e tecnologias de gestão, com vistas à prestação de serviços públicos de melhor qualidade.

Por exemplo, o direito ao exercício de poder e do controle por parte dos cidadãos é assegurado pela Constituição Federal de 1988, permitindo-lhes, junto aos Órgãos Públicos: peticionar junto aos Poderes Públicos para a defesa de seus direitos (Art. $5^{\circ}$ - XXXIV), obter certidões em repartições públicas (Art. $5^{\circ}-\mathrm{XXXV}$ ), fiscalizar as contas municipais (Art. $31^{\circ}$, $\S 3^{\circ}$ ), denunciar irregularidades ou ilegalidades (Art. $74^{\circ}, \S 2^{\circ}$ ), participar dos conselhos de gestão de saúde (Art. $198^{\circ}$ - III), assistência social (Art. 204 - II), e educação (Art. $206^{\circ}$ - VI), cooperar por meio de associações no planejamento municipal (Art. $29^{\circ}$ - XII), receber informações das autoridades (Art. $5^{\circ}$ - XXXIII), promover ações judiciais e representações (Art. $5^{\circ}$ - LXXIII) (BRASIL, 1988).

Da mesma forma o Decreto-Lei n. ${ }^{\circ}$ 201/67 autoriza o cidadão a denunciar o prefeito (BRASIL, 1967), e a Lei de Responsabilidade Fiscal (Lei Complementar $n^{\circ} 101$ de 2000), nos Arts. 48 e 49, assegura à população o acesso à prestação de contas, aos planos e diretrizes orçamentárias e demais instrumentos de transparência vinculados à gestão fiscal (BRASIL, 
2000).

Mas será que isso é possível no capitalismo? Tal modo de produção enseja uma remanejo de estruturas sociais e, consequentemente, estatais que viabilizassem tal controle.

Para Mészaros (1993), a função de controle social, no decurso do desenvolvimento humano, foi alienada do corpo social e transferida para o capital, "[...] que adquiriu assim, o poder de aglutinar os indivíduos num padrão hierárquico estrutural funcional segundo critérios de maior ou menor participação no controle da produção e da distribuição". (MESZÁROS, 1993. p.32).

Por outro lado, o autor destaca que no mundo contemporâneo, com a crise estrutural, as contradições do capitalismo tornam-se cada vez mais explosivas, demonstrando o caráter irracional do controle social. Em suas palavras: “[...] a crise que enfrentamos não se reduz simplesmente a uma crise política, mas trata-se da crise estrutural geral das instituições capitalistas de controle social na sua totalidade." (MÉSZÁROS, 1987, p.32).

As contradições do capitalismo atual se manifestam nos índices de pauperização, no desemprego crônico, na intensificação da taxa de exploração do trabalho, na devastação do meio ambiente, na amplitude da violência nas diversas esferas, nas formas de alienação, na desestruturação de relações sociais que configuram o status quo dominante. Com essas consequências sociais, assevera:

[...] a contradição [fundamental] entre uma perda efetiva de controle e a forma vigente de controle, o capital, que pela sua própria natureza somente pode ser controle dado que é constituído mediante uma objetificação alienada da função de controle, como um corpo reificado separado e em oposição ao próprio corpo social (MÉSZÁROS, 1987, p. 33; acréscimo no original).

A irracionalidade do controle demonstra o limite da expansão do capital sobre a sociedade, pois "[...] os limites do capital colidem com os limites da própria existência humana." (MÉSZÁROS, 1987, p. 37).

Em face da complexidade histórica do momento, para Mèszáros (1987) não causa espanto o surgimento e a disseminação da ideia do controle da sociedade pelos cidadãos. Embora importantes reações dos trabalhadores estejam ocorrendo, ainda demonstram que estas se constituem num controle restrito, tendo em vista que atingem aspectos da reprodução da força de trabalho e não o cerne do sistema do capital que funda a existência da questão social.

Outra questão a ser colocada é que, quanto maior for a transparência administrativa (informações públicas reais, acessíveis e que possam ser entendidas por todos), maiores serão 
as possibilidades de controle social das ações do poder público. Isso se torna dificultoso no capitalismo, visto que os veículos de comunicação de massa detêm o capital e transmitem a informação como querem e quando querem.

Ao compreender o ordenamento jurídico como um sistema aberto de princípios e regras, afirma-se que leis e regulamentos, ainda que exaustivamente explicativos e detalhados, não dão conta de fornecer respostas definitivas para problemas que envolvem um alto grau de complexidade, pois envolvem relações jurídicas e não jurídicas entre o Estado e os administrados e entre os administrados.

O controle social é exercido pelo cidadão diretamente ou pela sociedade civil organizada, e enquadra-se como modalidade de controle externo.

Analisando a realidade constitucional brasileira é possível identificar que não se cuidou de estabelecer ou definir um "modelo econômico" próprio. Em verdade, o artigo 170 cuidou de apresentar os princípios gerais da atividade econômica, enaltecendo os dois elementos fundadores da ordem econômica: a valorização do trabalho e a livre iniciativa:

Art. 170. A ordem econômica, fundada na valorização do trabalho humano e na livre iniciativa, tem por fim assegurar a todos existência digna, conforme os ditames da justiça social, observados os seguintes princípios:

I - soberania nacional;

II - propriedade privada;

III - função social da propriedade;

IV - livre concorrência;

$\mathrm{V}$ - defesa do consumidor;

VI - defesa do meio ambiente, inclusive mediante tratamento diferenciado conforme o impacto ambiental dos produtos e serviços e de seus processos de elaboração e prestação; (Redação dada pela Emenda Constitucional n ${ }^{\circ} 42$, de 19.12.2003)

VII - redução das desigualdades regionais e sociais;

VIII - busca do pleno emprego;

IX - tratamento favorecido para as empresas de pequeno porte constituídas sob as leis brasileiras e que tenham sua sede e administração no País. (Redação dada pela Emenda Constitucional n ${ }^{\circ}$ 6, de 1995)

Parágrafo único. É assegurado a todos o livre exercício de qualquer atividade econômica, independentemente de autorização de órgãos públicos, salvo nos casos previstos em lei. (BRASIL, 1988).

Apesar da aparente contradição da Carta de 1988, para José Afonso da Silva (1968, p. 762), não significa a adoção de outro sistema econômico que não o capitalista, posto que, no Brasil, a ordem econômica está apoiada inteiramente na apropriação privada dos meios de produção e na iniciativa privada (art. 170), o que 
[...] caracteriza o modo de produção capitalista, que não deixa de ser tal por eventual ingerência do Estado na economia nem por circunstancial exploração direta de atividade econômica pelo Estado e possível monopolização de alguma área econômica, porque essa atuação estatal ainda se insere no princípio básico do capitalismo que é a apropriação exclusiva por uma classe dos meios de produção, e, como é essa mesma classe que domina o aparelho estatal, a participação deste na economia atende a interesses da classe dominante $[\ldots]$

Sob tal constatação, o controle social a que se almeja no âmbito do capitalismo encontra óbices que estão encravados no próprio texto constitucional quando adotou os institutos básicos do modo de produção capitalista: a propriedade privada (arts. $5^{\circ}$, XXII e 170, II), a liberdade de contratar, a livre iniciativa (art. 170 "caput") e a livre concorrência (art. 170, IV), com a preferência da exploração econômica pela empresa privada (art. 173).

Em pleno século XXI, ainda existem gestores da coisa pública omitindo informações, transmitindo informações de forma equivocada e dificultando o acesso às informações, conforme destaca o autor:

Fica claro que os governos são os detentores das informações acerca do próprio governo, das políticas públicas, dos cidadãos e de toda uma extensa gama de assuntos de interesse público. Isto denota a existência de uma assimetria no acesso às informações, em detrimento da sociedade civil ou do cidadão considerado individualmente. (BEUTTENMULLER, 2007, p. 26).

No mesmo sentido, cita-se:

Porém, para que a participação seja qualificada e que o controle social seja efetivo, é necessário, antes de tudo, que os cidadãos tenham acesso à informação pública, pois esta é o expediente anterior à participação. A Lei $\mathrm{n}^{\circ}$. 12.527/11 (Lei de Acesso à Informação) tem a missão de promover a transparência pública e fomentar o controle social, este último entendido como participação do cidadão na gestão pública (vontade popular orientando a vontade político-administrativa do Estado e fiscalização voltada ao combate à corrupção e malversação dos recursos públicos). (ZIELINSKI, 2015, p. 41).

As múltiplas relações sociais que caracterizam a vida em uma sociedade democrática são marcadas por um elemento fundamental: a necessidade de o indivíduo fazer escolhas, as quais serão tão mais próximas do ponto ótimo almejado pelo indivíduo quanto mais informações ele ou ela detiver sobre as opções, os caminhos, as alternativas e as possibilidades disponíveis. O pressuposto desta ideia é que a tomada de decisões bem informadas beneficiará o indivíduo, enquanto decisões tomadas no escuro serão prejudiciais. 
Conhecer as informações em poder do Estado permite o monitoramento da tomada de decisões pelos governantes - que afetam a vida em sociedade. O controle social mais atento dificulta o abuso de poder e a implementação de políticas baseadas em motivações privadas. Ao mesmo tempo, decisões de políticas públicas tomadas com base em informações amplas e de qualidade terão resultados mais eficientes (CANELA, 2009).

A grande questão que se impõe é a realidade de econômica capitalista, fundada na exploração dos indivíduos pelos exploradores - detentores do capital, com a validação do Estado. Tal realidade impede que se exerçam, efetivamente, os direitos fundamentais esculpidos na Constituição. O que há é um falso exercício, com base em informações maquiadas por aqueles que controlam tudo, através do capital.

Nesse diapasão, Mascaro (2014) pontua que, no capitalismo, a forma política democrática está entranhada à forma jurídica, residindo aí seu detalhe, seu espaço típico e seus limites. Seu locus fundamental é o direito, desdobrado no plano eleitoral e no plano da Constituição e do resguardo da subjetividade mínima suficiente à reprodução do capital. Sendo cidadãos, os sujeitos de direito se tornam aptos a votar e serem votados.

Assim, derivada da forma-mercadoria, a forma política democrática estabelece correspondência entre sujeito de direito e cidadão, mas de forma frágil em face da manipulação de informações.

Mascaro, com acerto, assevera:

O sistema de comunicação talha diretamente a construção das vontades e das informações pertinentes. Além disso, e mais importante, não só quanto cargos e postos estão sob a disputa eleitoral nem apenas a qualidade dessa disputa, mas também o que está afastado dela é que revelará a conexão dinâmica, frágil e variável entre capitalismo e democracia. (MASCARO, 2014, s.p.).

Os cidadãos têm direito a participar dos assuntos públicos; trata-se do direito pertencente à esfera do status activae civitatis. Cada cidadão, como legítimo detentor do poder soberano do Estado, deve ter respeitado seu direito de participar de todas as esferas de decisão, seja contribuindo para a definição das políticas públicas a serem implementadas, seja controlando a ação voltada à efetivação de tais políticas. De fato, refere-se ao reconhecimento de que a esfera pública não diz respeito apenas ao Estado, mas sim a todos que dele fazem parte. A noção de público prevalecente no Estado Liberal e no Estado Social ou do Bem-Estar-Social, que remete à ideia de tudo que diga respeito à esfera estatal, não mais pode ser aceita no paradigma do Estado Democrático de Direito. Ao contrário, deve ser 
compreendida como esfera de todos, cidadãos e poderes instituídos (SILVA, 1983).

A questão é o modos operandi no capitalismo, o qual precisa ser alterado com urgência nem que seja pela superação do próprio modo de produção.

Há duas questões cruciais que envolvem "o acesso à informação", colocadas com muita propriedade por Seelaender (2006), que são a tecnocracia e a "distorção ou redução de dados" feita pelos meios de comunicação ao moldar as questões, visando atender à mídia e aos polos de poder político e econômico.

Em relação à tecnocracia, por mais que as informações sejam disponibilizadas em sua totalidade, haverá áreas que não serão compreendidas pelo homem comum por lhe faltar o conhecimento técnico específico, requerendo um processo permanente de tradução dessas informações técnicas, daí a opinião de Seelaender (2006), de que o "direito de ser informado" deve abranger o "direito à explicação", sob pena de se tornar disfuncional. Por outro lado, falta à sociedade o conhecimento necessário para decodificar as mensagens passadas pela mídia.

Nos últimos anos, assiste-se a uma mudança de postura da sociedade civil, embora voltado para a questão de comando político do país, deve ser considerada e enaltecida, pois demonstra uma saída da zona de conforto. Mas, no caso recente do impeachment da Presidente Dilma Rousseff, manipulado, também, pela força do capital através dos meios de comunicação de massa - especialmente aquele que é líder absoluto no mercado.

Mesmo havendo uma parcela de manipulação, os indivíduos estão exercendo um controle maior de que em tempos passados.

Se não houver apropriação e participação das decisões que traçam o rumo do país, fica bem mais difícil muda-lo para rumos melhores.

Assevera Caggiano ((2011, p.5):

Hoje, o cidadão não mais se satisfaz tendo assegurado o direito de sufrágio, o de eleger seus governantes/representantes. Busca mais: um canal de interveniência direta no polo decisional e uma via de controle sobre os denominados "decision makers". A participação vem sendo assegurada por mecanismos da democracia semi-direta, a exemplo do referendo, do plebiscito, da iniciativa popular e para o controle há, no Brasil, uma gama variada de instrumentos, inclusive instituições, como o Ministério Pública com a missão constitucional de manter vigilância quanto ao respeito à Constituição e à lei.

Diante da conjuntura exposta, ascende no Brasil um intenso debate em torno da "participação" no qual os mais diversos atores têm reivindicado a participação social, a 
democracia participativa, o controle social sobre o Estado, a realização de parcerias entre o Estado e a sociedade civil (ALBUQUERQUE, 2004).

Busca-se, com isso, consolidar a autonomia dos movimentos sociais frente ao governo, interrompendo, dessa forma, com a intervenção estatal em vigor desde a vitória do modelo de poder centralizado na esfera central, iniciado com o Estado Novo. Todas as lutas, movimentos e mobilizações sociais têm sido preponderantes para ampliação dos espaços de participação democrática consagrados na Constituição de 1988 que reconheceu e ampliou os direitos sociais, principalmente ao instituir espaços de formulação, gestão e controle das políticas sociais, viabilizados por meio de organizações representativas nos conselhos deliberativos (BULLA; LEAL, 2006).

Para corroborar com o pensamento aqui exposto, importante ressaltar o que diz Maciel (2007, p. 3):

Isto quer dizer que aceitar as ideias que defendem que o cidadão pode e deve encontrar no mercado os meios para a sua reprodução social é, no mínimo, uma posição ingênua. A cidadania é um produto construído em um ambiente contraditório em que a organização social e a participação cidadã são fundamentais para o reconhecimento e a legitimação dos indivíduos enquanto cidadãos. É por isso que deve ser vistas com muita reserva as adjetivações dadas constantemente para o cidadão, como por exemplo, o de cidadão consumidor, uma vez que estas qualificações tendem a destituir o caráter político que está contido no cerne do conceito de cidadão e de cidadania.

Devemos então perguntar: qual é o ambiente que nutre e alimenta a própria cidadania e, por correspondência fortalece o papel do cidadão no controle das políticas públicas? Obviamente que esse lugar é o ambiente democrático. Isto quer dizer que um ambiente democrático tem um grande efeito sobre a constituição de um Estado de direitos, que por princípio, se organiza para atender as necessidades sociais das maiorias sociais.

A postura do cidadão-administrado, como destinatário das ações do poder público, integra o rol das preocupações e/ou intervenções necessárias em busca do efetivo controle social e, consequentemente, de um maior sucesso nas ações governamentais que devem ser construídas não somente pelo Estado, mas em parceria com a sociedade.

Os entraves ao controle social, embora envolvam a esfera do indivíduo e a do Estado, inter-relacionam-se entre si, com uns exercendo influência sobre os outros, num processo de autoconstrução diária; por isso mesmo as ações minimizadoras dos efeitos de algum deles terão poder de influência sobre os demais. Entretanto, requer que sejam redescobertos outros mecanismos de superação, uma vez que as forças de contenção não se limitam às fronteiras do Estado-Nação, destacando-se como principais a deficiência da cidadania dos brasileiros, a 
falta de acesso à informação real e de qualidade e o excesso de uso da burocracia a serviço dos tecnocratas (SILVA, 2010).

Santos (2014, p. 11), ao dissertar sobre a "Minha escola transparente: uma análise comparativa do uso de dados governamentais abertos na educação básica no Brasil e Inglaterra", elenca pontos relevante a serem observados com relação às políticas públicas:

Neste contexto diferentes agendas podem atuar na dinâmica das políticas públicas: Entidades da sociedade civil fiscalizam a boa aplicação dos recursos e avaliam os resultados das políticas públicas qualificando o debate sobre sua eficácia; Empresas investem sua capacidade técnica para resolver problemas que o governo não teria condições de solucionar na velocidade e qualidade necessárias; Os agentes, burocratas, veem o resultado da gestão exposto aos "olhos invisíveis" da sociedade e utilizam os dados para definição de metas e objetivos; E o principal, cidadão usuário, tem à disposição ferramentas de transparência que sinalizam o desempenho e a qualidade dos serviços públicos.

Os resultados indicam que o êxito da avaliação de políticas públicas, como um mecanismo de controle democrático, passa, necessariamente, por duas condições: a difusão e a transparência das informações geradas com base nas avaliações e a incorporação de regras e procedimentos de fiscalização via participação social (CENEVIVA; FARAH, 2012).

Não é possível deixar de reafirmar que a fragilidade da democracia brasileira, em função do modo de produção capitalista, é um entrave ao atingimento do efetivo controle.

As principais ferramentas de controle social são conselhos de políticas, observatório social, orçamento participativo, audiência pública e ouvidoria. Cada uma tem a sua importância, mas deve-se investigar a forma de utilização, de maneira detalhada e individualizada, tendo em vista que a ferramenta pode ser boa, mas se mal utilizada ou subutilizada não atingirá a finalidade para a qual foi criada.

Nesse diapasão, as ouvidorias merecem destaque, pois interligam a vontade do cidadão à estrutura posta pelo Estado:

As ouvidorias estão incluídas neste trabalho como mecanismo de controle social, pois, ainda que sua estrutura seja vinculada aos órgãos da Administração Pública, o desencadeamento de soluções por parte deste órgão se principia a partir de manifestação por parte do cidadão. (MAGALHÃES, 2013, p. 98).

Nesse cenário, é inegável a relevância das leis recém-introduzidas no ordenamento jurídico brasileiro que consagram regras de materialização do princípio da transparência e do direito de acesso à informação, pois não bastam instrumentos e espaços para o exercício do controle pelo cidadão, faz-se imprescindível dotá-lo do necessário conhecimento. 
O Brasil vem, paulatinamente, às vezes com grande demora, conscientizando-se da necessidade de tornar as atividades da máquina estatal mais transparentes em busca de maior legitimidade de sua atividade política. Principalmente após a promulgação da Constituição Federal de 1988 essa necessidade tornou-se mais patente, e uma série de medidas vem sendo tomadas, assistematicamente, com o objetivo de divulgar informações de caráter público. $\mathrm{O}$ coroamento dessa percepção deu-se com a aprovação da Lei de Acesso à Informação analisada, a qual é uma lei bastante completa, com viés de abertura acentuado, contendo características existentes nas legislações mais modernas do mundo, benefício obtido por ser retardatário na produção desse marco legal. Porém, este fato não pode obscurecer a realidade do grande desafio que se descortina, exigindo-se a modificação da forma de pensar e entender a administração pública pela população e pela própria burocracia estatal, de tal forma que estes atuem em função e em benefício daqueles. Esse processo, corretamente conduzido, deve trazer um grande aprimoramento do sistema democrático no Brasil (LINHARES, 2011)

O que se busca é uma Administração Pública que fomente a participação da sociedade, através de uma atuação proativa, espontânea, com base na ética, em que "[...] o próprio serviço público é visto como uma extensão da cidadania, ele é motivado por um desejo de servir os outros e lograr objetivos públicos.” (DENHARDT, 2012, p. 269).

É possível concluir que da divulgação espontânea de informações pelo Estado (transparência ativa) e da solicitação de informações, ainda que não elencadas ou previstas em regulamentos (transparência passiva), nasce o saudável debate do que seja administração pública transparente, ou, para utilizar expressão recentemente consagrada, um governo efetivamente aberto.

Indicar meios e/ou formas do cidadão-administrado exercer controle sobre as ações governamentais com a finalidade de ver atingido o interesse público primário do Estado é, ainda, um grande desafio.

\section{CONCLUSÃO}

Diante de todo exposto, torna-se imperioso concluir que a saída da crise só acontecerá com o pós-capitalismo. O socialismo é colocado como alternativa, pois acaba com a mercadoria e tudo que a rodeia.

Nesse sentido, Garaudy diz: as contradições do capitalismo são tais que não há outra 
solução senão o socialismo para resolvê-las. Ora, nossa concepção da necessidade histórica é tal que ela requer, para a sua realização, nossa ativa, criadora participação.

A possiblidade real e efetiva de luta e transformação social, tendo por norte uma socialização democrática e estruturalmente justa, levava as posturas sociais a uma posição ativa, de construção e de esperanças, porque o sentido maior da história seria se abrir como possibilidade.

Mascaro (2015) afirma que o jurista só terá chance de ser autêntico duas vezes: quando no futuro, de fato, o direito for arte, ou seja, quando o capitalismo e suas formas sociais e jurídicas forem superados e em seu lugar surgir uma sociedade, fraterna e socialista, podendo julgar cada situação e cada coisa de acordo com sua justeza, ou então, atualmente, quando o jurista se engajar na luta pela transformação do mundo indiferente e capitalista num mundo fraterno e socialista.

A humanidade precisa aprender a compartilhar, sob pena de perpetuação da valorização da mercadoria, em detrimento do meio ambiente, da cidadania, da democracia e da igualdade material, os quais não são garantidos pelo Direito no capitalismo. Nesse processo, sempre inacabado, somente uma postura crítica acerca das práticas de cada um possibilita o resgate das melhores tradições e a superação daquelas que ameacem a efetiva vivência dos direitos fundamentais. Aqui está a necessidade de superação do capitalismo, o qual se mostra como grande empecilho.

A atitude do Direito é construtiva: sua finalidade, no espírito interpretativo, é colocar o princípio acima da prática para mostrar o melhor caminho para um futuro melhor, mantendo a boa-fé com relação ao passado; por último, uma atitude fraterna, uma expressão de como todos são unidos pela comunidade, apesar de divididos projetos, interesses e convicções.

A cooperação mútua entre Estado e sociedade é pressuposto para o atingimento dos fins do Estado - através de suas ações, bem como para a sua legitimação democrática.

Deseja-se uma nova interação entre cidadão-administrado e o Estado, pelo aperfeiçoamento do canal diálogo, especialmente daqueles voltados à conformação da norma jurídica e da tomada de decisão estatal, na medida em que se espera tornar informações mais acessíveis e transparentes, de forma a propiciar maior estabilidade nas relações entre Estado e sociedade, e, certamente, tudo isso só será plenamente possível com a superação do capitalismo. 
Ao analisar a participação dos trabalhadores no capitalismo, Paniago (2012, p.128 ) faz uma reflexão precisa:

Diante deste quadro histórico, da afirmação inconteste da produção destrutiva como modus operandi do sistema do capital, a possibilidade de haver um futuro para a humanidade coloca a necessidade urgente de uma alternativa social hegemônica que supere a ordem dominante. Isso exige da classe operária a reconstituição de uma estratégica e organização revolucionárias, orientadoras de toda luta emancipatória empreendida, que a leve a acumular forças no confronto com o capital, independentemente de garantias de vitórias imediatas. Desse modo, a investigação sobre a participação e o controle social a serem exercidos pelos trabalhadores não pode perder de vista sua finalidade emancipatória e nem deixar de reconhecer os requisitos fundamentais para a construção de uma sociedade socialista verdadeiramente autônoma, condições para que não nos confundamos com formas de pseudoparticipação e de pseudocontrole e nem nos conformemos por serem estas as únicas possíveis no interior dos quadros estruturais do capitalismo.

Realmente, não é possível satisfazer com "pseudoparticipação" e "pseudocontrole";

o que se deseja é uma participação real de todos os cidadãos, trabalhadores ou não, na gestão da coisa pública. A recém-citada autora continua:

Não basta ambicionar democratizar o capitalismo, o desafio é a superação do capital. Este é o princípio orientador de toda luta de classes, e estimulador de formas mais criativas e eficazes de participação e combate do trabalho nos diversos espaços político-sociais. O que exige a construção de bases prático-teóricas autênticas, que se contraponham ao rebaixamento teórico da classe trabalhadora, e evitem a acomodação e o conformismo diante das conquistas parciais possíveis, importantes, mas que permanecem aprisionadas pelos determinantes reprodutivos do capital, o que as torna absolutamente insuficientes para a verdadeira reconstituição do real poder de decisão dos verdadeiros sujeitos da produção. Trata-se da adoção de estratégias ofensivas que extravasem o campo do passado defensivo, superado pelo amadurecimento das contradições do próprio sistema. Em vista do caráter destrutivo e perdulário da produção imposta a toda a sociedade pela reprodução ampliada do capital em crise e os nefastos custos sociais provocados pelo desemprego estrutural e pela consequente degradação da condição de existência humana, ampliados à escala planetária (não se pode negar os dados assustadores sobre a fome no mundo), a constituição de uma forma alternativa de sociedade ao sistema do capital, que contemple a igualdade real entre todos os homens e uma produção e distribuição de riqueza humanamente autodeterminadas, é uma necessidade imperativa dada à ameaça de destruição da própria humanidade. (PANIAGO, 2012, p. 129).

Embora atrelada a toda e qualquer mudança estejam sempre presentes receios, entende-se que para o controle social, previsto na Constituição Federal, ganhar efetividade é necessário enfrentar os medos e os nossos desafios. A “[...] radical eliminação do capital 
pelos indivíduos autoemancipados de sua presente dominação do metabolismo social é o exato conteúdo do projeto socialista." (MÉSZÁROS, 2004, p. 516).

No mesmo sentido, Garaudy (1995) diz: as contradições do capitalismo são tais que não há outra solução senão o socialismo para resolvê-las. Ora, nossa concepção da necessidade histórica é tal que ela requer, para a sua realização, nossa ativa, criadora participação.

A humanidade precisa aprender a compartilhar; o capitalismo e suas formas sociais e jurídicas devem ser superados, no seu lugar deverá surgir uma sociedade fraterna.

\section{REFERÊNCIAS BIBLIOGRÁFICAS}

ALBUQUERQUE, M. do C.. Participação cidadã nas políticas públicas. In: HERMANNS, K. (org.). Participação cidadã - novos conceitos e metodologias. Fortaleza: Expressão Gráfica e Editora, 2004.

ALTHUSSER, Louis. Aparelhos ideológicos de estado. Rio de Janeiro: Civilização Brasileira, 2008.

BEUTTENMULLER, Gustavo. Observatórios locais de políticas públicas no Brasil: seu papel na produção, disseminação e transparência das informações. 2007. 247f.. Dissertação (Mestrado em Administração Pública e Governo). São Paulo, Fundação Getúlio Vargas, 2007.

BRASIL. Decreto-Lei 201 de 27 de fevereiro de 1967. Dispõe sôbre a responsabilidade dos prefeitos e vereadores, e dá outras providências. Diário Oficial da União - Seção 1 27/2/1967, Página 2348. Poder Executivo, Brasília, 2000.

BRASIL. Constituição (1988). Constituição da República Federativa do Brasil. Aprovada em 05 de outubro de 1988. Brasília: Senado Federal, 1988.

BRASIL. Constituição (1988). Lei Complementar 101 de 04 de maio de 2000. Lei de Responsabilidade Fiscal. Estabelece normas de finanças públicas voltadas para a responsabilidade na gestão fiscal e dá outras providências. Diário Oficial [da] União, Seção 1 - 5/5/2000, Página 1. Poder Executivo, Brasília, 2000.

BULLA, L. C.; LEAL, M. L. M.. A participação da sociedade civil no Conselho Municipal de Assistência Social: o desafio de uma representação democrática. Textos \& Contextos (Porto Alegre), v. 3, n. 1, 2006.

CAGGIANO, Monica Herman Salem. Democracia x constitucionalismo. Um navio à deriva? Cadernos de Pós-Graduação em Direito. São Paulo, nº 01, 2011. Disponível em: 
<http://www.direito.usp.br/pos/arquivos/cadernos/caderno_1_2011.pdf>Acesso em: 04 abr. 2018

CANELA, Guilherme; NASCIMENTO, Solano (coordenadores). Acesso à informação e controle social das políticas públicas. Brasília, DF: ANDI; Artigo 19, 2009.

CENEVIVA, Ricardo; FARAH, Marta Ferreira Santos. Avaliação, informação e responsabilização no setor público. Revista de Administração Pública, v. 46, nº 4, 2012 (p. 992-1016). Disponível em: <http://bibliotecadigital.fgv.br/ojs/index.

php/rap/article/view/7121> Acesso em: 17 jan. 2018.

DENHARDT, Robert B. Teorias da administração pública. São Paulo: Cengage Learning, 2012.

GARAUDY, Roger. Deus é necessário? Rio de Janeiro: Zabar, 1995.

LINHARES, Fernando Moura. $\mathrm{O}$ direito de acesso às informações públicas nas democracias representativas contemporâneas. 2011. Dissertação (Mestrado em Direito Constitucional) - Universidade de Fortaleza, Fortaleza, 2011.

MACIEL, Carlos Alberto Batista. Políticas públicas e controle social: encontros e desencontros da experiência brasileira. (2002). Disponível em:

<http://www.uniblog.com.br/esp-gestaoemsaude/485175/politicas-publicas-e-controle-socialencontros-e-desencontros-da-experiencia-brasileira>. Acesso em: 14 jan. 2018

MAGALHÃES, Roberto. Mecanismos sociais, políticos e jurídicos de controle da administração pública. 2013. 147f. Dissertação (Mestrado em Administração Pública). Universidade Federal de Lavras, Lavras, 2013.

MASCARO, Alysson Leandro. Estado e forma política. São Paulo: Boitempo, 2014.

MASCARO, Alysson Leandro. Crítica da legalidade e do direito brasileiro. São Paulo: Quartier Latin, 2003.

MASCARO, Alysson Leandro. Filosofia do direito. São Paulo: Atlas, 2014.

MASCARO, Alysson Leandro. Introdução ao estudo do direito. São Paulo: Atlas,2015.

MÉSZÁROS, István. A necessidade do controle social. São Paulo, Editora Ensaio, 1993 (Cadernos Ensaio, Pequeno Formato).

MÉSZÁROS, István. A necessidade do controle social. São Paulo, Editora Ensaio, 1987 (Cadernos Ensaio, Pequeno Formato).

MÉSZÁROS, István. O poder da ideologia. Tradução de Paulo Cezar Castanheira. São Paulo: Boitempo, 2004.

PACHUKANIS, Evgeni Bronislávovich. Teoria geral do direito e marxismo. São Paulo: 
Acadêmica, 1988.

PANIAGO, M. C. S.. Capital, controle social e participação autônoma dos trabalhadores no capitalismo em crise. 2012. Disponível em:

<http://www.scielo.br/pdf/rk/v15n1/a12v15n1.pdf>. Acesso em: 17 maio 2017.

SANTOS, Otávio Albuquerque Ritter dos. Minha escola transparente: uma análise comparativa do uso de dados governamentais abertos na educação básica no Brasil e Inglaterra. 2014. 90f. Dissertação (Mestrado em Administração Pública). Escola Brasileira de Administração Pública e de Empresas. Fundação Getúlio Vargas, Rio de Janeiro, 2014.

SEELAENDER, Airton Cerqueira-Leite. Democratização pelos "mass media"? - O direito de ser informado e os limites fáticos à sua plena eficácia. In: LIMA, Martonio Mont'Alverne Barreto; ALBUQUERQUE, Paulo Antônio de Menezes (Org.). Democracia, direito e política: Estudos internacionais em homenagem a Friedrich Müller. Florianópolis: Conceito Editorial, 2006.

SILVA, Elke Andrade Soares de Moura. Controle externo, controle social e cidadania. Revista do Tribunal de Contas do Estado de Minas Gerais. Ano 1, $\mathrm{n}^{\mathrm{o}} 1$, dez. 1983. Belo Horizonte, 1983

SILVA, Jacqueline Maria Cavalcante da. Controle social das políticas públicas no Brasil: caminho para uma efetiva democracia. 2010. 147f. Dissertação (Mestrado em Direito Constitucional). Fundação Edson Queiroz. Universidade de Fortaleza, Fortaleza,2010. Disponível em: <http://dominiopublico.mec.gov.br/download/teste/arqs/cp135433.pdf>. Acesso em: 17 jan. 2018.

SILVA, José Afonso da. Curso de direito constitucional positivo. 22. ed. São Paulo: Malheiros, 2003. p .762.

ZIELINSKI, Dioleno Zella. Controle social da administração pública: a lei de acesso à informação na perspectiva da dimensão da accountability societal. 2015. 130f. Dissertação (Mestrado em Direito do Estado). Universidade Federal do Paraná, Curitiba, 2015.

ZIZEK, Slavoj. Em defesa de causas perdidas. São Paulo: Boitempo, 2011. 